\title{
Postprandial Lipid Abnormalities in Type 2 Diabetes Mellitus, A Study at NGMC, Kohalpur
}

\author{
A. Shukla
}

\begin{abstract}
Aim and Objectives: To study the postprandial lipid abnormalities in patients with type 2 diabetes mellitus. Material and Methods : Postprandial lipids were studied in 40 male type 2 diabetic subjects (age $49.75 \pm 4.82$ years) and 40 age and sex matched healthy controls (age $49.55 \pm 4.82$ years) after an oral fat challenge which consisted of a meal providing $729 \mathrm{kcal} / \mathrm{m} 2 \mathrm{body} \mathrm{surface}$ area with $68 \mathrm{gm}$ fat. Results: Average duration of diabetes among diabetic was $2.32 \pm 3.03$ years. The body mass index (cases $25.84 \pm 4.52$; controls $25.74 \pm 5.0 ; p>0.05$ ) and waist-hip ratio (cases $1.06 \pm 0.13$; controls $1.14 \pm 0.2 ; p>0.05$ ) were similar in both groups. While fasting serum lipids were not significantly different between the two groups, a number of serum lipid abnormalities were noted in type 2 diabetic subjects in the postprandial state. These included a higher triglyceride-area under curve (AUC) (cases $1298.08 \pm 485.2$ vs. controls $922.15 \pm 390.47 \mathrm{mg} / \mathrm{dl} / 8 \mathrm{~h} ; \mathrm{p}=0.01$ ), a higher triglyceride-area under incremental curve (AUIC) (cases $549.68 \pm 382.24$; control $294.75 \pm 172.6 \mathrm{mg} / \mathrm{dl} / 8 \mathrm{~h} ; \mathrm{p}=0.01$ ), a higher peak triglyceride level (cases $425.2 \pm 204.47 \mathrm{mg} \%$, controls $283.9 \pm 11.6 .94 \mathrm{mg} \%$, $\mathrm{p}=0.01$ ), a lower HDL-AUC (cases $130.35 \pm 33.55$ vs. controls $168.48 \pm 56.01 \mathrm{mg} / \mathrm{dl} / 8 \mathrm{~h}, \mathrm{p}=0.013$ ) and a lower HDL nadir (Cases $28.05 \pm$ $10.94 \mathrm{mg} \%$, controls $37.13 \pm 13.52 \mathrm{mg} \%, \mathrm{p}<0.02)$. Triglyceride AUC correlated significantly with fasting serum triglyceride $(r=0.62)$ and BMI ( $r=0.7)$, but not with waist hip ratio. Postprandial lipaemia did not correlate with age, duration of diabetes, fasting blood glucose or glycosylated hemoglobin. Conclusion: In conclusion, type 2 diabetics demonstrate significant postprandial lipid abnormalities, particularly of triglycerides, which appear to be independent of glycaemic control.
\end{abstract}

Key words: Lipids, post prandial, type 2 diabetes

\section{INTRODUCTION}

Type 2 diabetes mellitus is associated with the development of premature arteriosclerosis and a higher cardiovascular morbidity and mortality ${ }^{1-3}$. Diabetic dyslipidaemia is believed to play an important role in the pathogenesis of accelerated atherosclerosis in this condition ${ }^{4-5}$. The predominant lipid abnormalities seen in diabetes mellitus are an elevated serum triglyceride ( $\mathrm{Tg}$ ) level and a low HDL-C level.6 While several studies have found a significant association of fasting hypertriglyceridaemia, ${ }^{5,7,8}$ and coronary artery disease (CAD) in diabetes mellitus, the relationship is not consistent particularly after adjusting for fasting HDL-C Levels9. It is being increasingly believed that atherosclerosis is a postprandial phenomenon as at least with respect to lipids, we are in the postprandial phase for most of the day ${ }^{10,11,13}$. High postprandial triglycerides have shown a strong and independent association with ${ }^{11,12}$. Earlier studies of postprandial lipids in diabetes mellitus have suggested abnormalities of $\mathrm{Tg}$ metabolism ${ }^{13,14}$ secondary to insulin resistance ${ }^{15}$ although results have not been consistent $^{16}$. We have examined the postprandial lipid responses to a standard fat challenge in diabetic patients to characterize the nature and extent of postprandial lipaemia ${ }^{17}$.

\section{Address for correspondence:}

Dr. Avikal Shukla

Department of Medicine

Nepalgunj Medical College Teaching Hospital

Kohalpur, Banke, Nepal

Email: shuklaavikal@yahoo.com

\section{MATERIAL AND METHODS}

An oral fat challenge was given to 40 male type 2 diabetic patients and 40 age, sex and BMI matched healthy controls who had no family history of diabetes. Diabetes was diagnosed as per revised ADA criteria and were either newly diagnosed or off treatment for 2 weeks.

The present study was conducted at NGMC, Kohalpur between March 2012 to February 2013. Patients with fasting triglyceride level (FTG )>250 mg/dl, nephropathy, hepatic disease, hypothyroidism, Cushing's disease, inherited disorders of lipid metabolism, clinical or ECG evidence of CAD, alcoholism, smoking or use of medication affecting lipids were excluded. An oral glucose tolerance test was performed in all healthy controls to rule out diabetes, Impaired Fasting Glucose (IFG) and Impaired Glucose Tolerance (IGT). All subjects diabetic patients and control were hospitalised after preliminary clinical \& lab assessment. These included fasting plasma glucose (FPG), 2 hrs postprandial plasma glucose (PPPG), Glycosylated Hemoglobin, lipid profile, kidney \& liver function tests, X-ray chest and an electro cardiogram. After a 14 hour overnight fast, a standardised meal was given to all subjects providing 729 $\mathrm{kcal} / \mathrm{sq} \mathrm{m}$ body surface area (BSA) (65.2g fat/sq. m BSA;). Blood was drawn at 0, 2, 4, 6 and 8 hours for glucose, and lipids estimation. Serum was separated and stored at - 20oc for various estimations.

\section{RESULTS}

Table I shows the baseline characteristics of patients with type 2 diabetes mellitus. Diabetic subjects were middle aged (mean age $49.75 \pm 8.86$ years), with a mean body mass index (BMI) of 
$25.84 \pm 4.52 \mathrm{~kg} / \mathrm{sq} \mathrm{m}$ and waist/hip ratio of $1.06 \pm 0.13$ suggestive of central obesity. Diabetic subjects were matched for age, BMI, waist/hip ratio with controls.

The fasting lipid profile in type 2 diabetes patients (Table II) differed from controls only in a significantly lower HDL-C value $(35.15 \pm 10.84 \mathrm{mg} / \mathrm{dl}$ vs. $42.9 \pm 14.11 \mathrm{mg} / \mathrm{dl})$. There was no significant difference in any of the other lipid parameters in the fasting state.

Significant postprandial lipid abnormalities were observed in the diabetic subjects particularly of Tg and HDL-C (Table III). Triglyceride area under the curve, postprandial triglyceride area under incremental curve and peak postprandial triglyceride levels were all significantly higher in diabetic subjects compared to controls (Figure. 1 and 2). In the case of HDL-C, while the HDL-C nadir and HDL-C Area under the curve were significantly lower than controls there was no difference once adjustment was made for fasting HDL-C values and area under decremental curves were compared.

Table IV shows the correlation of postprandial triglyceride parameters with various baseline variables. Clearly, postprandial triglyceridaemia showed significant correlation only with $\mathrm{BMI}$ and fasting $\mathrm{Tg}$ values but not with age duration of diabetes or any other measure of glycemic (FPG, PPPG and $\left.\mathrm{HbA}_{1} \mathrm{c}\right)$.

\begin{tabular}{|l|c|c|c|}
\hline & Diabetic patients & Control & P \\
\hline Age (yrs) & $49.75 \pm 8.86$ & $49.55 \pm 4.82$ & 0.93 \\
\hline Duration of DM (yrs) & $2.32 \pm 3.03$ & - & - \\
\hline BMI (kg/sq m) & $25.84 \pm 4.52$ & $25.74 \pm 5.0$ & 0.94 \\
\hline Waist/ Hip & $1.06 \pm 0.13$ & $1.14 \pm 0.20$ & 0.16 \\
\hline $\mathrm{HbA}_{1} \mathrm{c}(\%)$ & $8.59 \pm 1.28$ & $5.01 \pm 0.43$ & $<0.01$ \\
\hline
\end{tabular}

Table I : Baseline characteristics of study population

\begin{tabular}{|l|c|c|c|}
\hline & Diabetic patients & Control & P \\
\hline $\mathrm{TC}(\mathrm{mg} / \mathrm{dl})$ & $209.45 \pm 40.27$ & $197.6 \pm 57.13$ & 0.35 \\
\hline $\mathrm{HDL}-\mathrm{C}(\mathrm{mg} / \mathrm{dl})$ & $35.15 \pm 10.84$ & $42.9 \pm 14.11$ & 0.06 \\
\hline $\mathrm{LDL}-\mathrm{C}(\mathrm{mg} / \mathrm{dl})$ & $138.4 \pm 37.15$ & $117.0 \pm 49.47$ & 0.13 \\
\hline $\mathrm{VLDL}-\mathrm{C}(\mathrm{mg} / \mathrm{dl})$ & $37.4 \pm 12.76$ & $32.2 \pm 14.54$ & 0.237 \\
\hline $\mathrm{TG}(\mathrm{mg} / \mathrm{dl})$ & $187.1 \pm 63.45$ & $156.85 \pm 76.57$ & 0.18 \\
\hline
\end{tabular}

VLDL-C $=$ VLDL Cholesterol, TG $=$ Triglycerides, $\mathrm{TC}=$ Total Cholesterol, HDL-C $=$ HDL Cholesterol, LDL-C $=$ LDL Cholesterol

Table II : Fasting lipid profile of diabetic subjects

\begin{tabular}{|l|c|c|c|}
\hline & Diabetic patients & Control & P \\
\hline TC- AUC & $836.92 \pm 187.81$ & $797.7 \pm 218.2$ & 0.546 \\
\hline TG- AUC & $1298.08 \pm 485.2$ & $922.15 \pm 390.47$ & 0.010 \\
\hline HDL-C AUC & $130.35 \pm 33.55$ & $168.48 \pm 56.01$ & 0.013 \\
\hline TC- AUIC & $0.88 \pm 89.29$ & $19.3 \pm 70.83$ & 0.43 \\
\hline TG- AUIC & $549.68 \pm 382.24$ & $294.75 \pm 172.6$ & 0.01 \\
\hline HDL-C AUIC & $10.25 \pm 22.69$ & $3.13 \pm 20.94$ & 0.309 \\
\hline Peak TC & $232.45 \pm 53.13$ & $210.35 \pm 54.31$ & 0.201 \\
\hline Peak TG & $425.2 \pm 204.47$ & $283.9 \pm 116.94$ & 0.01 \\
\hline HDL-C nadir & $28.05 \pm 10.94$ & $37.15 \pm 13.52$ & 0.02 \\
\hline
\end{tabular}

$A \cup C=$ area under curve $(\mathrm{mg} / \mathrm{dl} / 8$ hours $) ; A U I C=$ area under incremental curve $(\mathrm{mg} / \mathrm{dl} / 8$ hours $)$

Table III: Postprandial lipid profile in diabetic subjects 


\begin{tabular}{|l|c|c|c|c|c|c|c|c|}
\hline & Age & Duration & BMI & W/H & HbA $_{1} \mathbf{C}$ & FPG & FTG & FI \\
\hline TG AUC & 0.009 & -0.075 & $\begin{array}{c}0.703^{* *} \\
\text { P=0.001 }\end{array}$ & 0.370 & 0.120 & -0.073 & $\begin{array}{c}0.624^{*} \\
\text { P=0.011 }\end{array}$ & 0.238 \\
\hline Peak TG & 0.084 & -0.217 & 0.516 & 0.163 & 0.109 & -0.100 & 0.375 & 0.130 \\
\hline
\end{tabular}

$\mathrm{W} / \mathrm{H}=$ Waist $/$ Hip Ratio, FPG = Fasting Plasma Glucose, $\mathrm{FTG}=$ Fasting Triglycerides, $\mathrm{FI}=$ Fasting Insulin

Table IV : Correlations of postprandial hypertriglyceridemia among diabetic subjects

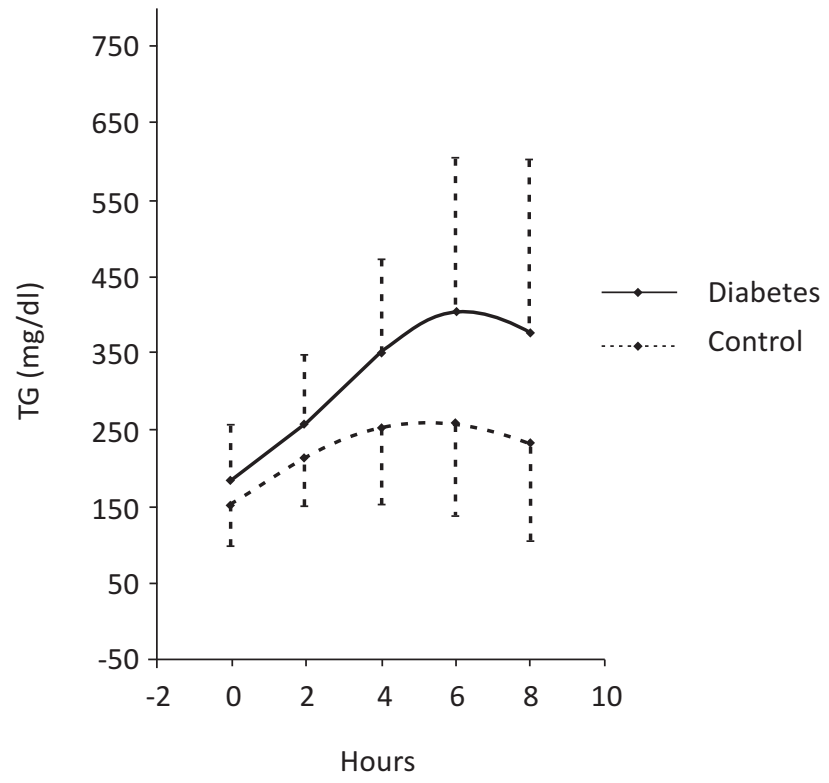

Figure 1: Area under curve for triglycerides following oral fat challenge in patients with type 2 diabetes mellitus.

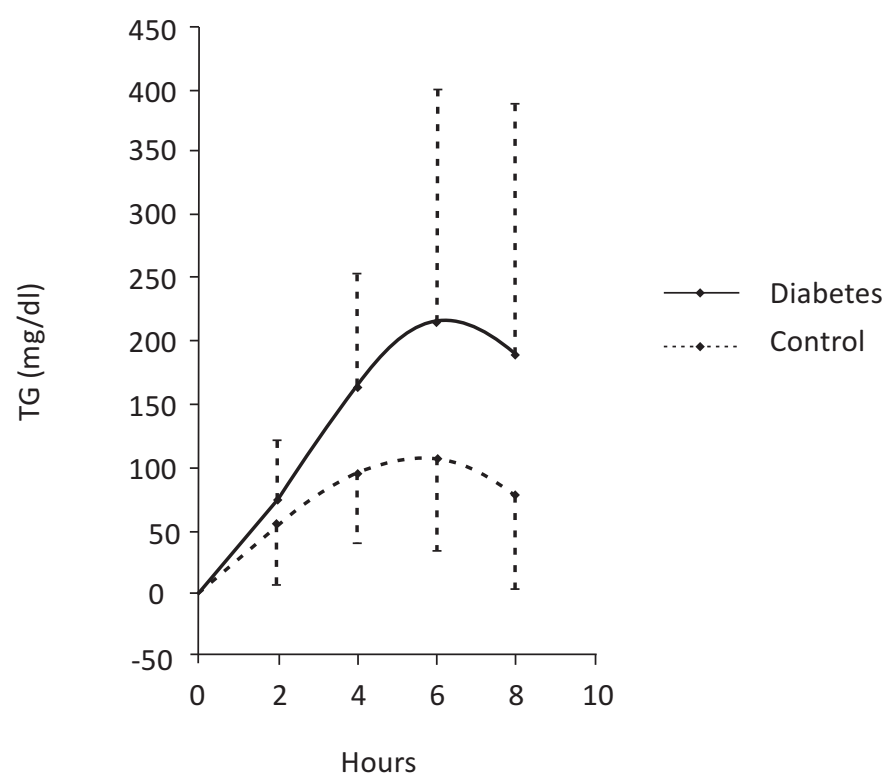

Figure 2 : Area under incremental curve for triglycerides following oral fat challenge in patients with type 2 diabetes mellitus.

\section{DISCUSSION}

The present study clearly demonstrates an altered postprandial (PP) response of serum triglycerides $(\mathrm{Tg})$ following oral fat challenge in male type 2 diabetes subjects compared to controls. The PP hypertriglyceridaemia remained significant even after adjusting for fasting $\mathrm{Tg}$ levels and was present despite similar fasting $\mathrm{Tg}$ levels in diabetic patients and controls. To the best of our knowledge, this is the first report of abnormal postprandial triglyceridaemia among diabetic patients from Nepal and highlights that at least in diabetic subjects, estimating lipids in the postprandial phase may be far more important than in the fasting state.

Exaggerated PP triglyceridaemic responses have been shown in patients with diabetes mellitus by few ${ }^{13,14}$ while other have failed to demonstrate such a difference ${ }^{16}$. However, these responses were observed only in diabetic patients whether obese $^{13}$ or non obese ${ }^{16}$ who displayed moderate fasting hypertriglyceridaemia. Once diabetic subjects were matched with controls for fasting $\mathrm{Tg}$ levels in addition to age, gender and body mass index then PP hypertriglyceridaemia too was not significantly different ${ }^{16}$. In general, the relationship between fasting $\mathrm{Tg}$ and postprandial lipaemia in patients with NIDDM was similar to that in non-diabetic individuals ${ }^{14}$. PPTg responses significantly correlated with fasting $\mathrm{Tg}$ concentration in the diabetic group suggesting higher the fasting $\mathrm{Tg}$ Concentration greater was the degree of PP lipaemia ${ }^{16}$. Whether it is the fasting Tg level which determines PPTg level in these patients as interpreted by previous workers or it is the magnitude of the PPTg response that determines the fasting Tg level, is not very clear. On the basis of our findings, as well as others it would appear that it is the PP triglyceridemia that determines fasting $\mathrm{Tg}$ levels. The postprandial $\mathrm{Tg}$ levels peaked at 6-8 hrs after a high fat meal and still remained close to the peak in most patients even after $8 \mathrm{hrs}$. Fasting Tg levels estimated 12-14 hours after the previous meal would thus represent the Tg value recorded on the down slope of the PPTg response curve 4-6 hours after its peak.

The diabetic state itself appears to be a major factor contributing to the abnormal PPTg response among type 2 diabetic patients as other confounders of altered PP lipid 
responses such as age, sex, body mass index and measures of central obesity have been carefully controlled in this study. Earlier studies have reported that postprandial lipid metabolism could by altered by factors such as obesity, ${ }^{13}$ insulin resistance, $^{15}$ age $^{18}$ and visceral obesity ${ }^{19}$. The influence of diabetic state on PP triglyceride metabolism even after controlling for obesity has not been reported earlier. This effect however, seems to be independent of current or previous glycemic control, as we did not find a significant correlation of PP lipaemia with any of the glycemic parameters studied. Obesity also appears to influence PP lipaemia in type 2 DM as high PP triglycerideaemia showed good correlation with body mass index. Thus, it would appear that the magnitude of PP Tg response in type 2 diabetic subjects is largely determined by an interaction of obesity and the underlying diabetic state.

Insulin resistance has been shown to be important in regulating the postprandial concentration of triglycerides and triglycerides rich lipoproteins $(T R L)^{15}$. The current study found no correlation of waist/hip ratio, consid- ered to be marker of insulin resistance, with PP lipaemic response parameters. These findings would seem to argue against a major role of insulin resistance in post- prandial fat metabolism at least in diabetic subjects.

Several underlying mechanisms have been postulated for the exaggerated PPTg response in diabetes mellitus. Although, this has not been resolved completely, delayed clearance of TRL secondary to decreased LPL activity is believed to be the most important mechanism with some contribution from excessive hepatic Tg production ${ }^{20,21}$.

\section{CONCLUSION}

Male type 2 diabetic patients demonstrate significant postprandial triglyceride abnormalities which appear to be independent of glycemic control.

\section{REFERENCES}

1. Garcia MJ, Mc Namara PM, Gordon T, Kannel WB. Morbidity and mortality in diabetics in the Framingham population, Sixteen year follow-up study. Diabetes 1974;23:105-11.

2. Fagan TC, Sowers J. Type 2 diabetes mellitus- greater cardiovascular risks and greater benefits of therapy. Arch Intern Med 1999;159:1033-34.

3. Haffiner SM, Lehto'S, Ronnemaa T, Pyorala K, Laakso M. Mortality from coronary heart disease in subjects with type 2 diabetes and in non-diabetic subjects. N Engl J Med 1998;339:229-34.

4. Fontbonne A. Relationship between diabetic dyslipoproteinemia and coronary heart disease risk in non-insulin dependent diabetes. Diabetes Metab Rev 1991;7:179-89.

5. Fontbonne $A$, Eschewege $E$, Cambien $F$, et al. Hypertriglyceridemia as a risk factor for coronary heart disease mortality in subjects with impaired glucose tolerance or diabetes: Results from 11 year follow up of the Paris Prospective study. Diabetologia 1989;32:300-04.
6. Taskinen M. Quantitative and qualitative lipoprotein abnormalities in diabetes mellitus. Diabetes 1992;41:12-17.

7. Hobanson JE, Austin MA. Plasma triglyceride level is a risk factor for cardiovascular disease independent of high density lipoprotein cholesterol level: a meta-analysis of population based prospective studies. J Cardiovasc Risk 1996;3:213-19.

8. West KM, Ahuja MMS, Bennet PH, Czyzyk A, DeA costa OMD, Fuller JH, Grab B, Grabauskas V, Jarrett RJ, Kusaka K, Keen H, Krolewski AS, Miki E, Schilack V, Teuschev A, Watkins PJ, Stober JA. Role of circulating glucose \& triglyceride concentrations and their interaction with other risk factors as determinants of arterial disease in nine diabetic population samples from the WHO Multicenter Study. Diabetes Care 1983;6:361-69.

9. Assmann G, Schulte H. Relationship of high density lipoprotein cholesterol and triglyceride to incidence of atherosclerotic coronary artery disease (The PROCAM experience). Am J Cardiol 1992; 70:733-41.

10. Zliversmit DB. Atherosclerosis: a postprandial phenomenon. Circulation 1979; 60:472-85.

11. Patsch JR, Miesenbock G, Hopferwieser T, Muhlberger V, Knapp E, Dunn JK, Patsch W. Relation of triglyceride metabolism and coronary heart disease: Studies in the postprandial state. Arteriosclerosis and Thromb 1992;12:1336-45.

12. Ryu JE, Howard G, Craven TE, Bond MG, Hagman AP. Postprandial triglyceridemia and carotid atherosclerosis in middle aged subjects. Stroke 1992;23:823-28.

13. Lewis GF, O'Meara NM, Soltys PA, Blackman JD, Iverius PH, Pugh WL, Getz GS, Polonsky KS. Fasting Hypertriglyceridemia in noninsulin dependent diabetes mellitus is an important predictor of postprandial lipid and lipoprotein abnormalities. J Clin Endocrinol Metab 1991;72:934-44

14. Chen YD, Swami S, Skowronski R, Coulston A, Reaven GM Differences in postprandial lipemia between patients with normal glucose tolerance and non-insulin dependent diabetes mellitus. J Clin Endocrinol Metab 1993;76:172-77.

15. Jeppensen J, Hollenbeck CB, Zhou MY, Coulston AM, Jones C, Chen YD. Relation between insulin resistance, hyperinsulinemia, postheparin plasma lipoprotein lipase activity and postprandial lipaemia. Atherioscler Thromb Vasc Biol 1995;15:320-24.

16. Cavallero E, Brites F, Delfy B, Nicofaiew N, Decossin C, Geitere GD, Fruchart JC, Wikinski R, Jacotot B, Castro G. Abnormal reverse cholesterol transport in controlled type II diabetic patients. Arterioscler Thromb Vasc Biol 1995;15:2130-35.

17. McKeigue PM, Marmot MG, Adeletoin AM. Diet and risk factors for CAD in Asians in Northwest London. Lancet 1985;2:1086-90.

18. Cohn JS, McNamara JR, Cohn SD, Ordovas JM, Schaefer EJ. Postprandial plasma lipoprotein changes in human subjects at different ages. J Lipid Res 1988;29:469-75.

19. Couillard C, Bergeron N, Prudhomme D, Bergeron J, Tremblay A, Bouchard C, Mauriege P, Despres JP. Postprandial triglyceride responsible in visceral obesity in men. Diabetes 1998;47:95360.

20. Pfeifer MA, Brunzell JD, Best JD, Judzewitsch RG, Halter JB, Porte DJ. The response of plasma triglyceride, cholesterol and lipoprotein lipase to treatment of non-insulin dependent diabetic subjects without familial hypertriglyceridemia. Diabetes 1983;32:525-31.

21. Nikkila EA, Huttunen JK, Ehnholm C. Postheparin plasma lipoprotein lipase and hepatic lipase in diabetes mellitus relationship to plasma triglyceride metabolism. Diabetes 1977;26:11-21. 